\title{
Only one English test required for overseas trained healthcare professionals
}

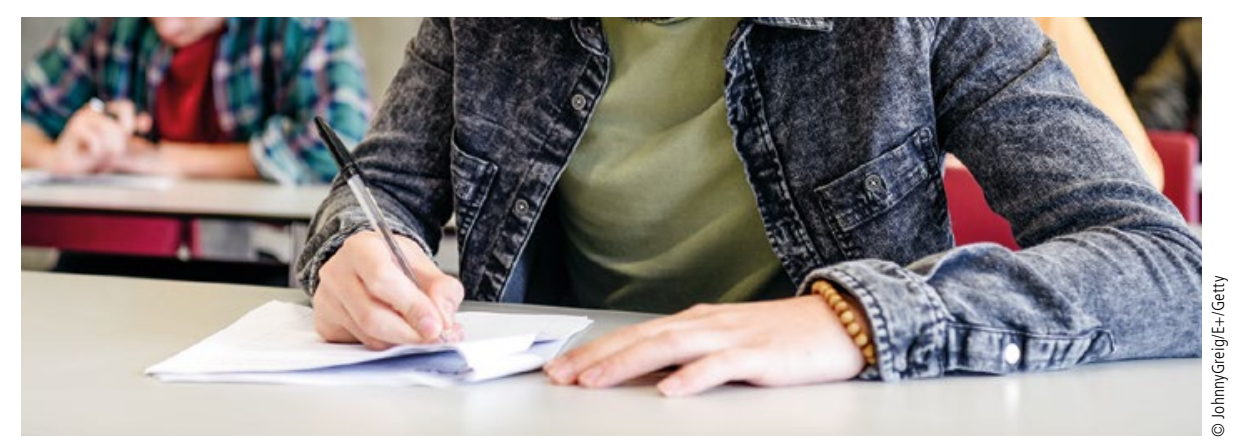

The Royal College of Surgeons of Edinburgh (RCSEd) is extremely concerned about the potential effect a no deal Brexit could have on UK healthcare and patient safety. One area of concern is the mutual recognition of professional qualifications which currently allows EU doctors' qualifications to be accepted across the EU. It has been confirmed that the Mutual Recognition of Professional Qualification Directive will continue until 2020. Following this, further legislation comes into effect which will enable UK regulators to continue to recognise EEA and Swiss qualifications.

The RCSEd said that it is essential that the qualifications of doctors, and other healthcare professionals, continue to be recognised permanently following Brexit. Doctors from the EU are essential to the running of the NHS and will remain a key resource in the years to come. It must continue to be as easy as possible for the NHS to recruit EEA doctors; the alternative is an NHS under even more strain due to falling numbers of doctors.

RCSEd President, Professor Michael Griffin OBE, said: 'The NHS is under extreme pressure at the moment and one of the major causes is a recruitment crisis within the medical and nursing workforces. Teams are working harder than ever and it is vital to ensure that surgical teams are fully staffed in order to operate safely and ensure patient safety. A no deal Brexit and along with it the potential for disruption to the recruitment of medical and nursing staff could be extremely damaging to the NHS and have a knock-on impact on patient waiting times for elective operations. The Government must ensure that the recruitment of EEA medics and nurses is not hampered following Brexit.'

The Home Office has announced that doctors, dentists, nurses and midwives who have already passed an English language test accepted by the relevant professional body, do not have to sit another test before entry to the UK on a Tier 2 visa (general visa). This change will make sure that hospitals and practices across the country will be able to access the staff they need more quickly.

This means that these healthcare professionals will be exempt from the English language requirement for their visa application where they have used their successful Occupational English Test (OET) results for registering with the relevant healthcare regulator.

- According to a White Paper published by OET and the Joint Commission International exploring common communication problems in healthcare, 'Studies have clearly shown that poor or missing communication between providers and patients can lead to patient harm or even death $^{1}$

- A 2013 systematic review of over 900 studies concluded that empathy is 'the backbone of the patient-physician relationship', 'lowers patient anxiety and distress, and delivers significantly better clinical outcomes ${ }^{2}$
- OET is accepted by relevant professional bodies in the UK including the General Medical Council, the Nursing and Midwifery Council, the Royal College of Emergency Medicine, the Royal College of Ophthalmologists, the Royal College of Veterinary Surgeons, and Edinburgh's Royal College of Physicians and Royal College of Surgeons.

The change will apply to all Tier 2 (General) visa applications submitted on or after 1 October 2019. It will enormously reduce the burden on overseas trained professionals seeking to work in the UK, and enable the NHS and healthcare recruiters to fulfil their staffing requirements with overseas trained healthcare professionals who have the communication skills to deliver safe and effective care.

\section{References}

1. Joint Commission International. Communicating clearly and effectively to patients. How to overcome common communication challenges in health care. A White Paper by Joint Commission International. 2018. Available at: https://www.jointcommissioninternational.org/ assets/3/7/JCI-WP-Communicating-Clearly-FINAL_(1). PDF (accessed September 2019).

2. Derksen F, Bensing J, Lagro-Janssen A. Effectiveness of empathy in general practice: a systematic review. $\mathrm{Br} J$ Gen Pract 2013; 63: e76-e84.

\section{BDA AGMs}

The South Yorkshire BDA Branch is holding its AGM on 6.30-9 pm on 16 October 2019 at Double Tree by Hilton Sheffield Park, followed by a lecture on 'Applying the New Periodontal
Classification in Practice. The Eastern Counties Branch AGM is also on 16 October at Ravenwood Hall, Rougham, Bury St Edmunds, from 8-9 pm. To book a place at either event visit www.bda.org/bse. 